\title{
New records of Philometra pellucida (Jägerskiöld, 1893) (Nematoda: Philometridae) from the body cavity of Arothron mappa (Lesson) and Arothron nigropunctatus (Bloch et Schneider) reared in aquariums, with synonymisation of Philometra robusta Moravec, Möller et Heeger, 1992
}

Takashi Iwaki ${ }^{1}$, Kenta Tamai ${ }^{2}$, Keisuke Ogimoto $^{2}$, Yuka Iwahashi ${ }^{3}$, Tsukasa Waki ${ }^{1,4}$, Fumi Kawano $^{1}$ and Kazuo Ogawa

\author{
${ }^{1}$ Meguro Parasitological Museum, Meguro-ku, Tokyo, Japan; \\ ${ }^{2}$ Shimonoseki Marine Science Museum, Shimonoseki, Yamaguchi, Japan; \\ ${ }^{3}$ SEA LIFE Nagoya, Minato-ku, Nagoya, Aichi, Japan; \\ ${ }^{4}$ Present address: Graduate School of Science, Toho University, Funabashi, Chiba, Japan
}

\begin{abstract}
We encountered two cases of infection with large female nematodes of the genus Philometra Costa, 1845 in the body cavity of a map puffer Arothron mappa (Lesson) caught off Okinawa, Japan, and a blackspotted puffer Arothron nigropunctatus (Bloch et Schneider) caught off Queensland, Australia, both reared in aquariums in Japan. No morphological difference was observed between the nematodes from A. mappa and A. nigropunctatus. We identified the nematodes as Philometra pellucida (Jägerskiöld, 1893) based on their morphology. The sequences of the nematodes from both hosts were identical to each other $(1,643 \mathrm{bp})$ and formed a clade with other 17 nematodes belonging to the genera Philometra and Philometroides Yamaguti, 1935 with high bootstrap value (bp $=100)$. It is the first time that the genetic data on P. pellucida are provided. Philometra robusta Moravec, Möller et Heeger, 1992 is synonymised with the former species.
\end{abstract}

Keywords: Nematodes, aquarium fish, Tetraodontiformes, Japan, Australia, morphology, 18S ribosomal DNA

To date, a total of 20 nominal species of philometrid nematodes (Philometridae) have been reported from marine fishes in Japanese waters (Moravec et al. 2019). From tetraodontiform fishes, only one species, Philometra pellucida (Jägerskiöld, 1893), was reported off Okinawa, Japan, whereas the other species of Philometra Costa, 1845 were recorded outside Japan (Moravec et al. 2018).

Recently, we encountered two cases of infection with large female nematodes of the genus Philometra in the body cavity of a map puffer Arothron mappa (Lesson) and a blackspotted puffer Arothron nigropunctatus (Bloch et Schneider), both reared in aquariums in Japan. We identified the nematodes as $P$. pellucida morphologically and genetically and discussed the possible synonymy of Philometra robusta Moravec, Möller et Heeger, 1992, with this species.

In the first case, A. mappa was caught in Kin Bay, Okinawa, Japan $\left(34^{\circ} 20^{\prime} \mathrm{N} ; 132^{\circ} 55^{\prime} \mathrm{E}\right)$ in November 2016 and transferred to Shimonoseki Marine Science Museum, Japan. First, the puffer had been kept in an acclimatisation tank for about two and a half months together with
Echeneis naucrates Linnaeus and Takifugu porphyreus (Temminck et Schlegel). At the time of introduction, the fish was lean with a deflated abdomen and took no food. After one week, it began to take food and the body began to appear normal, but feeding was not stable with alternate periods of feeding and non-feeding in the acclimatisation tank, often showing a deflated abdomen.

Subsequently, the puffer was moved to a 16.2-ton exhibition aquarium with other puffers such as Arothron reticularis (Bloch et Schneider), Arothron hispidus (Linnaeus), Arothron manilensis (Marion de Procé), Diodon hystrix Linnaeus, Chilomycterus reticulatus (Linnaeus), Balistoides viridescens (Bloch et Schneider) and Pseudobalistes fuscus (Bloch et Schneider). The fish had been given only frozen squid until it died in August 2017, after rearing of about six months in the exhibition aquarium. Thirty-nine large nematodes were obtained from the body cavity of this map puffer.

In the second case, A. nigropunctatus was caught in Arlington Reef, Queensland, Australia ( $\left.16^{\circ} 42^{\prime} \mathrm{S} ; 146^{\circ} 03^{\prime} \mathrm{E}\right)$ in June or August 2018 and transferred to SEA LIFE Nagoya, 


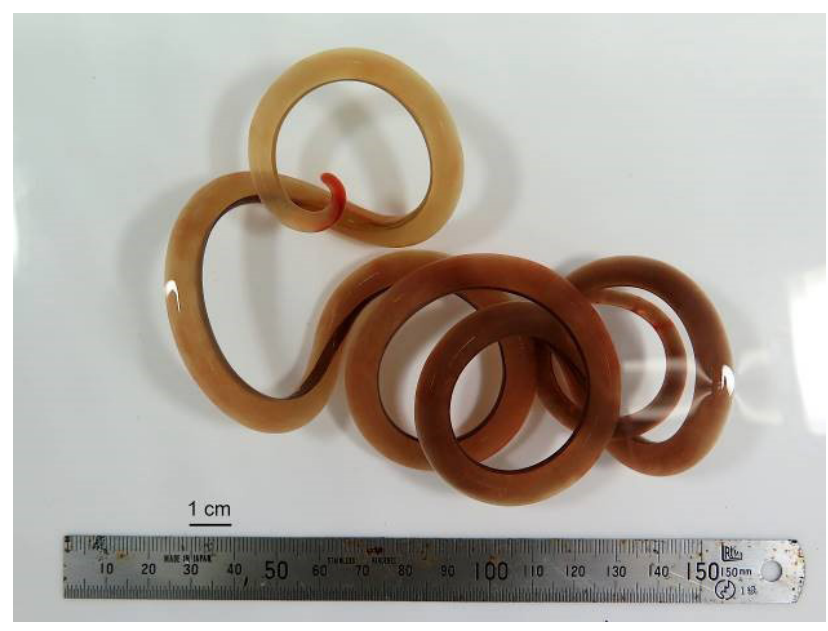

Fig. 1. A gravid female of Philometra pellucida (Jägerskiöld, 1893) from Arothron mappa (Lesson), Japan.

Japan in October 2018. The puffer had been kept in a temporary tank for several hours. Subsequently, it was moved to a 2-ton exhibition tank. It was reared with other fish from Australia such as Abudefduf vaigiensis (Quoy et Gaimard), Acanthurus triostegus (Linnaeus), Chrysiptera cyanea (Quoy et Gaimard), Gymnothorax enigmaticus McCosker et Randall, and Monodactylus argenteus (Linnaeus), but there were no puffers in the tank. The fish had been given foods like frozen Manila clams, krills and mysids and formulated dry pellets. It began to take food in a few days and appeared normal until it died in February 2019. Only one large nematode was obtained from the body cavity of this blackspotted puffer.

The nematodes obtained were washed in saline and fixed and preserved in 70\% ethanol. For light microscopical examination, the head and tail parts of the nematodes were cut and cleared in glycerine. Observation and morphometric measurements were performed with an optical microscope (Nikon Eclipse 80i) and a digital camera (Nikon DS-L2). Length and maximum width of the body were measured on photographs on a computer using ImageJ (image processing program - Schneider et al. 2012). The measurements of nematodes from $A$. mappa were taken from five specimens except for the lengths and maximum widths of bodies $(\mathrm{n}=15)$, and those from $A$. nigropunctatus were based on one specimen. All measurements are given in micrometres unless otherwise indicated (mean in parentheses). The specimens have been deposited in the Meguro Parasitological Museum (MPM Coll. Nos. 21650, 21651). The fish nomenclature adopted follows FishBase (Froese and Pauly 2019).

An alkaline lysate of one adult worm from each host was made from a piece of tissue from the frozen specimens by the same method described in Nakao et al. (2017). The lysates were used as templates for the polymerase chain reaction (PCR) to amplify nuclear $18 \mathrm{~S}$ ribosomal DNA (rDNA). We used the primer set 988F, 1912R, 1813F and 2624R for 18S rDNA (Holterman et al. 2006); PCR amplification and subsequent sequencing were performed by the same method as in Waki et al. (2018). Phylogenetic tree was built by using the Maximum Likelihood (ML) method and Kimura 2-parameter model (Kimura 1980) of MEGA $\mathrm{X}$ (Kumar et al. 2018). Bootstrapping with 1,000 replicates was conducted for the ML tree.

Morphological observation (Figs. 1, 2). Specimens from Arothron mappa: Body very long. Length of body of ethanol-fixed specimens 351-651 mm (527 mm; $\mathrm{n}=15) \mathrm{mm}$, maximum width 6.3-10.4 mm (7.9 mm; $\mathrm{n}=15) \mathrm{mm}$; maximum width/body length ratio $1: 54-76$ (1:67). Cephalic end rounded. Oral aperture oval. Three oesophageal lobes protruded from mouth or not. Oesophagus muscular, with funnel- or bulb-shaped inflation at anterior end, 178-210 (191) long, 224-247 (235) wide. Length of entire oesophagus $1.76-2.69 \mathrm{~mm}(2.11 \mathrm{~mm})$, maximum width of the posterior part 182-222 (209). Nerve ring 372-521 (427) from anterior end. Ventriculus 39-81 (59) long, 109-143 (130) wide. Vulva and anus absent. Ovaries short, situated close to anterior and posterior ends of body. Uterus occupies most space of body, filled with numerous larvae. Larvae 419-476 (438; $\mathrm{n}=10$ ) long, 16-19 (17) wide. Posterior end of female curved ventrally with rounded tip. Caudal projections not observed.

Specimen from $A$. nigropunctatus: Length of body $571 \mathrm{~mm}$, maximum width $7.7 \mathrm{~mm}$; maximum width/body length ratio $1: 74$. Bulb-shaped inflation of oesophagus 228 long, 295 wide. Length of entire oesophagus $2.25 \mathrm{~mm}$, maximum width of the posterior part 212. Nerve ring 434 from anterior end. Ventriculus 50 long, 146 wide. Larvae 331-416 (374; $\mathrm{n}=10$ ) long, 14-19 (17) wide. Other characteristics are coincident with those of the specimens from A. mappa described above.

The sequences of the nematodes we sampled from A. mappa and A. nigropunctatus were identical to each other (1,643 bp). The present sequences have been deposited on DDBJ/EMBL/GenBank databases with accession numbers LC536677 and LC536678 from A. mappa and $A$. nigropunctatus, respectively. These sequences formed a clade with other 17 nematodes belonging to the genera Philometra and Philometroides Yamaguti, 1935 with high bootstrap value (100\%). In addition, the present sequences formed a clade with Philometra lagoxephali Moravec et Justine, 2008 (KP122959) with relatively high bootstrap value (86\%) (Fig. 3).

Ten species of Philometra with gravid females of 200 $\mathrm{mm}$ or more in length are known: Philometra amazonica Travassos, 1960; Philometra balistii (Rasheed, 1963); Philometra cephalus Ramachandran, 1975; Philometra globiceps (Rudolphi, 1819); Philometra isaki Quiazon, Yoshinaga et Ogawa, 2008; Philometra lateolabracis Yamaguti, 1935; Philometra madai Quiazon, Yoshinaga et Ogawa, 2008; P. pellucida; P. robusta; and Philometra managatuwo Yamaguti, 1941 (see Moravec et al. 1992, 2018, Quiazon et al. 2008).

Meanwhile, the following seven nominal species of Philometra are reported from tetraodontiform fishes: $P$. balistii from Abalistes stellaris (Bloch et Schneider) and Balistes sp. in the Indian Ocean and the Red and South China Seas; Philometra damriyasai Dewi et Palm, 2017 from Tylerius spinosissimus (Regan) from the South Bali 

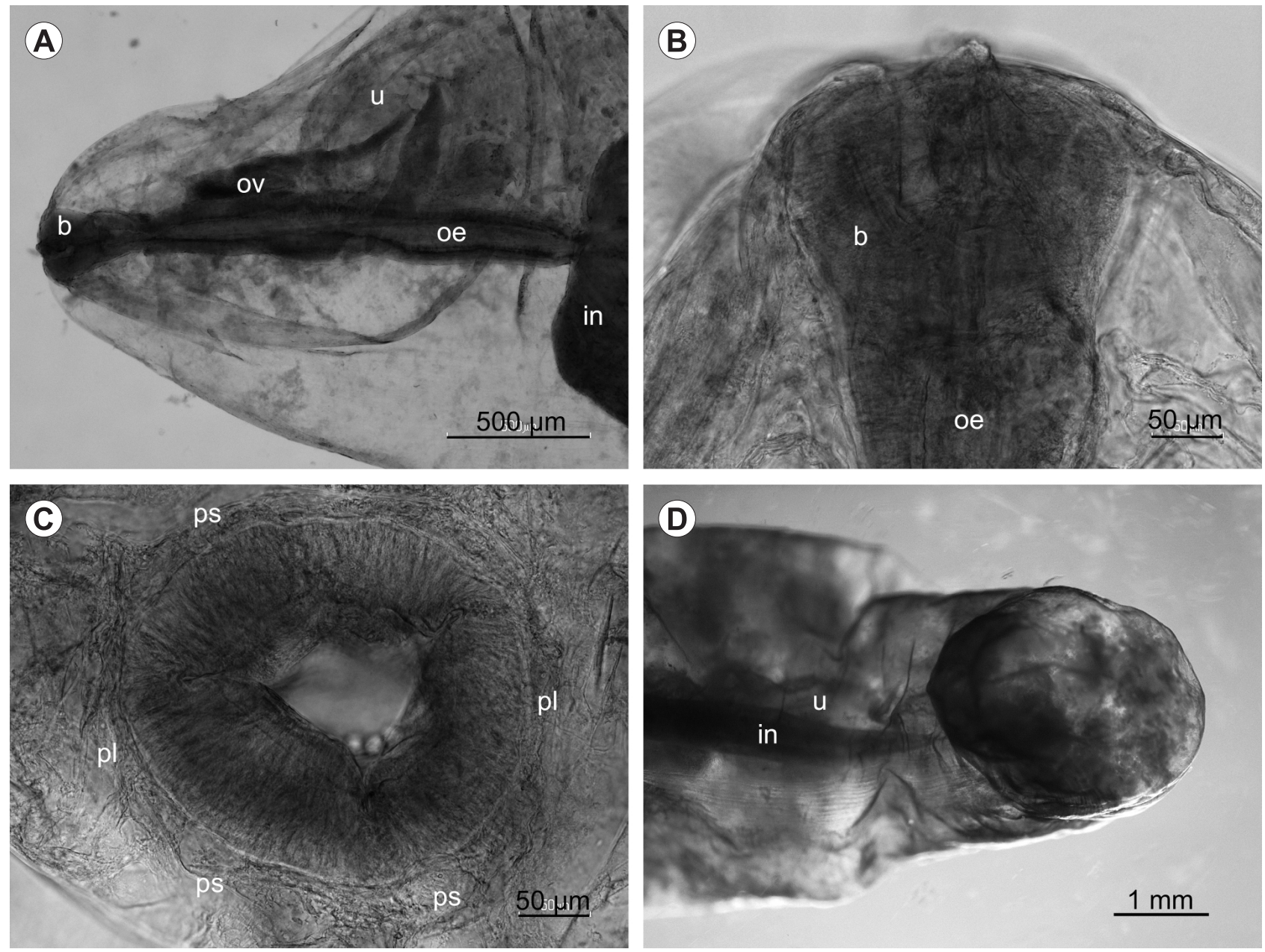

Fig. 2. Philometra pellucida (Jägerskiöld, 1893) from Arothron mappa (Lesson), Japan, gravid females. A - anterior end, lateral view; B, C - cephalic end, lateral and apical view, respectively; D - posterior end, ventral view. Abbreviations: $\mathrm{b}$ - bulb-shaped inflation of oesophagus; in - intestine; oe - oesophagus; ov - ovary; pl - lateral cephalic papillae; ps - submedian cephalic papillae; $\mathrm{u}$ - uterus.

Sea off Indonesia; Philometra javaensis Moravec, Walter et Yuniar, 2012 from Arothron immaculatus (Bloch et Schneider) in the Indian Ocean off Java, Indonesia; Philometra lagocephali Moravec et Justine, 2008 from Lagocephalus sceleratus (Gmelin, 1789) and L. lunaris (Bloch et Schneider, 1801) in the South Pacific Ocean off New Caledonia and the South China Sea off China, respectively; P. pellucida from Arothron stellatus (Anonymous) from the Java Sea off Indonesia and A. nigropunctatus from in the Coral Sea off Queensland, Australia and off Okinawa, Japan; $P$. robusta from A. mappa off the Philippines; and Philometra thaiensis Moravec, Fiala et Dyková, 2004 from freshwater puffers Dichotomyctere fluviatilis (Hamilton), D. ocellatus (Steindachner) and Pao palembangensis (Bleeker) in Thailand. These species of Philometra were collected from the body cavity of their host fishes, all belonging to the family Tetraodontidae, except for $P$. balistii, which infects the oculo-orbits of its hosts (Quiazon et al. 2014, Moravec et al. 2018). In addition to above species, an unidentified species, Philometra sp., was reported by Deardorff and Stanton (1983) from the abdominal cavity of Canthigaster jactator (Jenkins) (Tetraodontidae) in Hawaii. Moravec et al. (1992) pointed out a possible affinity of this unidentified species of Philometra with P. robusta.

Among the nominal species of Philometra parasitic in the body cavity of tetraodontiform fishes, gravid females of only two species, $P$. pellucida and $P$. robusta, are 200 $\mathrm{mm}$ or more long (Moravec et al. 1992, 2018). Moravec et al. (2018) provided the identification key to the species of Philometra parasitic in tetraodontiform fishes. Whereas the body lengths of the above two species overlapped (P. pellucida: $132-475 \mathrm{~mm}$, P. robusta: $275-450 \mathrm{~mm}$ ), the authors showed a differentiation point that there are two minute papilla-like projections at the caudal end of gravid female of $P$. robusta.

In the present study, no morphological difference was observed between the nematodes from $A$. mappa and $A$. nigropunctatus. They have been morphologically identified as $P$. pellucida because of the absence of minute caudal projections.

We compared the sequences of specimens from the above-mentioned fish hosts. The $18 \mathrm{~S}$ rDNA sequences $(1,643 \mathrm{bp})$ of two specimens were identical to each other and thus are considered conspecific (Fig. 3). The genetic data on $P$. pellucida are provided for the first time. How- 


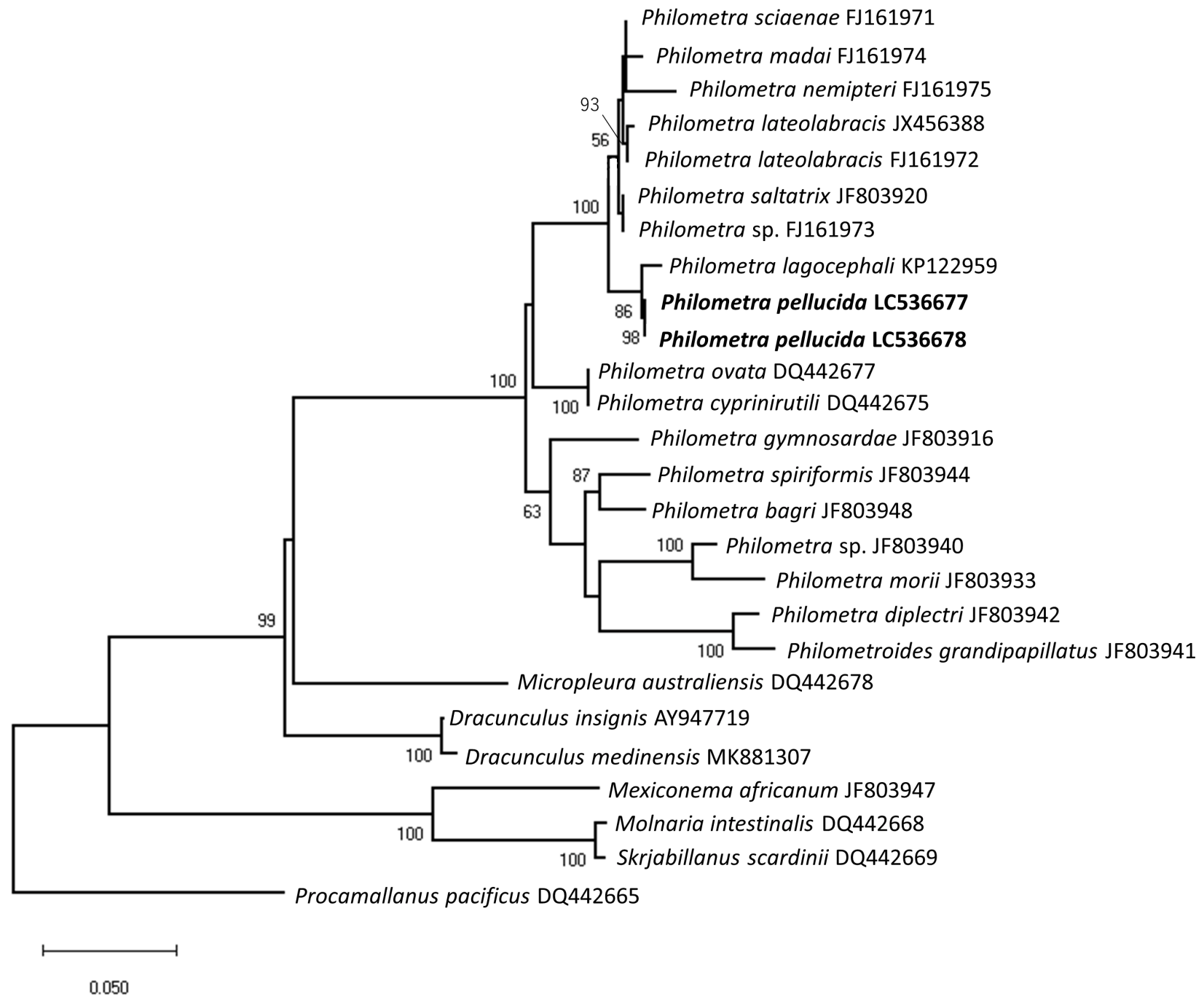

Fig. 3. Maximum-likelihood phylogenetic trees inferred from partial nucleotide sequences of $18 \mathrm{~S}$ rDNA of species of Philometra Costa, 1845 . Newly obtained sequences are in bold. Bootstrap percentages are shown on representative nodes. Bootstrap values above $50 \%$ are shown. The outgroup is Procamallanus pacificus Moravec, Justine, Wurtz, Taraschewski et Sasal, 2006 (DQ442665).

ever, comparison of $P$. pellucida with P. robusta is impossible because no molecular data are available for the latter species.

Regarding two species of the host fish in the present study, P. robusta was found in A. mappa off the Philippines (Moravec et al. 1992), whereas $P$. pellucida in A. nigropunctatus from the Coral Sea off Queensland, Australia and off Mizugama, Okinawa, Japan (Moravec et al. 2018). These nematodes were collected in the similar areas as those dealt with in the present study ( $A$. mappa in Okinawa, Japan, and A. nigropunctatus off Queensland, Australia). We compared the morphological descriptions of these two species (Moravec et al. 1992, 2018), but could not find any apparent differences except minute caudal projections. It is considered that the presence/absence of minute caudal projections is not a quite reliable feature to distinguish between Philometra spp., because such small projections may be easily overlooked or be absent in some specimens (F. Moravec, personal communication). Regarding our specimens from A. mappa and A. nigropunctatus, there were no differences in the morphological and genetic data between the specimens from these hosts, suggesting that these nematodes are conspecific. Considering these points, it is concluded that $P$. robusta is a junior synonym of $P$. pellucida.

Philometrids with known life cycles use copepods as intermediate hosts; some species with a piscivorous definitive host may utilise fish paratenic hosts as the main source of infection (Moravec 2004). In the present cases, A. mappa and $A$. nigropunctatus may have got infected by feeding on infected copepods and/or paratenic fish hosts when they were reared at the aquariums for several months. For one of large Philometra species, P. madai (identified by Sakaguchi et al. $1987 \mathrm{~b}$ as P. lateolabracis - Quiazon et al. 2008, Moravec et al. 2019), development from third-stage larva to adult takes two years (Sakaguchi et al. 1987a). The life cycle of $P$. pellucida is unknown, but is likely that the fish had already been infected with the nematodes before introduced to the aquariums.

We had never experienced a case of puffers with alternating periods of feeding and non-feeding, causing a deflated abdomen during the non-feeding periods. The heavy 
nematode infection may have caused such a deflated abdomen. It makes a good contrast with a similar case of a heavy nematode infection of the Hawaiian puffer fish, $C$. jactator, which showed a distended abdomen (Deardorff and Stanton 1983).

\section{REFERENCES}

Acknowledgements. We would like to thank František Moravec of the Institute of Parasitology, Biology Centre of the Czech Academy of Sciences, Czech Republic, and Shokoofeh Shamsi of Charles Sturt University, Australia, for valuable information and advice. We also thank the staff of the Shimonoseki Marine Science Museum and the SEA LIFE Nagoya for their kind support.
Deardorff T.L., Stanton F.G. 1983: Nematode-induced abdominal distention in the Hawaiian puffer fish, Canthigaster jactator (Jenkins). Pac. Sci. 37: 45-47.

Froese R., Pauly D. (Eds.) 2019: FishBase. World Wide Web electronic publication, www.fishbase.org, version (08/2019).

Holterman M., Van Der Wurff A., Van Den Elsen S., Van Megen H., Bongers T., Holocachoc O., Bakker J., HelDER J. 2006: Phylum-wide analysis of SSU rDNA reveals deep phylogenetic relationships among nematodes and accelerated evolution toward crown clades. Mol. Biol. Evol. 23: 1792-1800.

Kimura M. 1980: A simple method for estimating evolutionary rate of base substitutions through comparative studies of nucleotide sequences. J. Mol. Evol. 16: 111-120.

Kumar S., Stecher G., Li M., Knyaz C., Tamura K. 2018 MEGA X: Molecular Evolutionary Genetics Analysis across computing platforms. Mol. Biol. Evol. 35: 1547-1549.

MoraVEC F. 2004: Some aspects of the taxonomy and biology of dracunculoid nematodes parasitic in fishes: a review. Folia Parasitol. 51: 1-13.

Moravec F., Cutmore S.C., Yong R.Q. 2018: Redescription of Philometra pellucida (Jägerskiöld, 1893) (Nematoda: Philometridae) parasitic in the abdominal cavity of the blackspotted puffer Arothron nigropunctatus (Bloch and Schneider) (Teleostei: Tetraodontidae) off Australia and Japan. Syst. Parasitol. 95: 665-671.

Moravec F., Möller H., Heeger T. 1992: Philometra robusta sp. n. from the abdominal cavity of the scribbled toadfish, Arothron mappa from the Philippines. Folia Parasitol. 39: 227-234.

Moravec F., Nagasawa K., Nitta M., Tawa A. 2019: New records of philometrids (Nematoda: Philometridae) from marine fishes off Japan, including description of Philometra kidakoi sp. n. and Congerinema japonicum gen. et sp. n. Folia Parasitol. 66: 021.

Nakao M., Waki T., Sasaki M., Anders J. L., Koga D., Asakawa M. 2017: Brachylaima ezohelicis sp. nov. (Trematoda: Brachylaimidae) found from the land snail Ezohelix gainesi, with a note of an unidentified Brachylaima species in Hokkaido, Japan. Parasitol. Int. 66: 240-249.

Quiazon K.M.A., Yoshinaga T., Doi H., Araki J., Ogawa K. 2014: First description of male Philometra thaiensis Moravec, Fiala et Dykova, 2004 (Nematoda: Philometridae) from the body cavity of the eyespot pufferfish Tetraodon biocellatus Tirant, and evolutionary relationships of this species with other dracunculoids as inferred from SSU rRNA gene sequences. Helminthologia 51: 236-245.

Quiazon K.M.A., Yoshinaga T., Ogawa K. 2008: Taxonomical study into two new species of Philometra (Nematoda: Philometridae) previously identified as Philometra lateolabracis (Yamaguti, 1935). Folia Parasitol. 55: 29-41.

Sakaguchi S., Shibahara T., Yamagata Y. 1987a: Parasitic ecology of a Philometra lateolabracis parasite on the red sea bream. Bull. Natl. Res. Inst. Aquacult. 12: 73-78. (In Japanese, with English summary.)

SAKaguchi S., Yamagata Y., SAKo H. 1987b: Reidentification of Philometra parasitic on the red sea bream. Bull. Natl. Res. Inst. Aquacult. 12: 69-72. (In Japanese, with English summary.)

Schneider C. A., Rasband W. S., Eliceiri K. W. 2012. NIH Image to ImageJ: 25 years of image analysis. Nat. Methods 9: 671-675.

Waki T., Nakao M., Hayashi K., Ikezawa H., Tsutumi N. 2018: Molecular and morphological discrimination of dicrocoeliid larvae (Trematoda: Digenea) from terrestrial mollusks in Japan. J. Parasitol. 104: 660-670.

Cite this article as: Iwaki T., Tamai K., Ogimoto K., Iwahashi Y., Waki T., Kawano F., Ogawa K. 2020: New records of Philometra pellucida (Jägerskiöld, 1893) (Nematoda: Philometridae) from the body cavity of Arothron mappa (Lesson) and Arothron nigropunctatus (Bloch et Schneider) reared in aquariums, with synonymisation of Philometra robusta Moravec, Möller et Heeger, 1992. Folia Parasitol. 67: 025. 